\title{
Diversidade beta de plantas que oferecem néctar como recurso floral aos beija-flores em cerrados do Brasil Central
}

\author{
$\beta$-Diversity of hummingbird plants in cerrado areas of Central Brazil
}

\author{
Adriana Oliveira Machado \& Paulo Eugênio Oliveira
}

\begin{abstract}
Resumo
Os ambientes abertos de Cerrado têm sido considerados ambientes marginais ou complementares para beija-flores, apesar do registro de considerável número de espécies deste grupo de visitantes florais. Estes utilizam uma variedade de plantas, incluindo aquelas sem características ornitófilas. O objetivo do trabalho foi investigar a flora utilizada por beija-flores como recurso alimentar em três áreas de Cerrado, distantes entre si de ca. 20 a $150 \mathrm{~km}$. Em cada área foram demarcados, em cerrado s.s., dois transectos de 1 ha cada, que foram percorridos quinzenalmente para identificação das espécies utilizadas pelos beija-flores, os quais também foram identificados. A riqueza de espécies de plantas encontrada (26) foi maior que a registrada em outros estudos na mesma região, porém foi menor que na maioria dos ambientes florestais. Destas espécies, apenas nove (34\%) apresentaram síndrome de ornitofilia. Foram registradas nove espécies de beija-flores (Trochilidae) nas três áreas. Apesar da grande diversidade beta descrita para plantas no Cerrado, a similaridade de espécies utilizadas pelos beija-flores foi alta entre os transectos das três áreas estudadas, independente de serem plantas tipicamente ornitófilas ou não. Havia plantas oferecendo recursos florais para os beija-flores durante praticamente todo o ano. O grande número de espécies não ornitófilas utilizadas por estas aves corrobora a ideia de que, em ambientes de Cerrado, as espécies vegetais que oferecem néctar parecem ser mais importantes para os beija-flores que vice-versa.
\end{abstract}

Palavras-chave: Savana brasileira, Ornitofilia, Trochilidae.

\begin{abstract}
The open savanna areas of the Cerrado region in Central Brazil have been considered as marginal or complementary habitats for hummingbirds, despite the considerable number of hummingbirds recorded. These birds use a variety of plants without ornithophilous caracteristcs. The objective of the study was to investigate the flora used by hummingbirds as food resource in three Cerrado areas 20 to $150 \mathrm{~km}$ apart. In each of these cerrado s.s. areas, two transects of 1 ha each were walked fortnightly to identify the plant species used by hummingbirds, which were also identified. The number of plant species recorded (26) was higher than that observed for other studies in the same region but was lower than that recorded for forest habitats. Only nine plants (34\%) showed a truly ornithophilous syndrome. There were nine hummingbird species (Trochilidae) in the three areas. Although the Cerrado flora has been characterized by its high $\beta$-diversity, the hummingbird plants among transects and areas were very similar. Despite being truly ornithophilous or not, there were plants offering nectar to hummingbirds year round. The indiscriminate use of non-ornithophilous species corroborates the idea that, in Cerrado habitats, nectariferous plants seem to be more important to hummingbirds than vice-versa.
\end{abstract}

Key words: Brazilian savanna, Ornithophily, Trochilidae.

Universidade Federal de Uberlândia, Inst. Biologia, bl. 2D, Campus Umuarama, 38405-320, Uberlândia, MG, Brasil.

Autor para correspondência: adrianaoliveiramachado@yahoo.com.br 


\section{Introdução}

Embora tenha uma flora com riqueza comparável a de florestas tropicais (Felfili et al. 2008), e uma considerável variedade de beijaflores, ca. 36 espécies (Macedo 2002), o Cerrado tem relativamente poucas espécies de plantas claramente ajustadas à síndrome de ornitofilia. O sistema de polinização por insetos, sobretudo abelhas, predomina sobre os demais (Oliveira \& Gibbs 2000, 2002; Gottsberger \& SilberbauerGottsberger 2006; Martins \& Batalha 2006; Barbosa \& Sazima 2008). Embora a estimativa seja de que $7,5 \%$ da flora do Cerrado seja composta por espécies ornitófilas (Gottsberger \& SilberbauerGottsberger 2006), estudos em comunidades específicas revelaram porcentagens ainda menores (1,8 a 3,0\%) (Silberbauer-Gottsberger \& Gottsberger 1988; Borges 2000; Oliveira \& Gibbs 2000; Barbosa \& Sazima 2008). As condições ambientais de alta temperatura e baixa umidade são apontadas como causas da baixa riqueza de flores ornitófilas no Cerrado, fazendo com que alguns autores caracterizem-no como um ambiente marginal, um habitat secundário para os beijaflores, ou uma extensão das áreas de florestas (Gottsberger \& Silberbauer-Gottsberger 2006).

Apesar da baixa ocorrência de espécies essencialmente ornitófilas no Cerrado, estudos mais recentes têm mostrado que os beija-flores visitam muitas espécies de plantas não ornitófilas (Oliveira \& Gibbs 2000; Araújo et al. 2011; Araújo et al. 2013; Maruyama et al. 2013). A utilização de grande número de espécies com outras síndromes de polinização pelos beija-flores no Cerrado pode ser em função da pouca ocorrência de grupos de plantas tipicamente ornitófilas como Bromeliaceae, mas também porque estes beija-flores podem ter capacidade de explorar recursos regionalmente vantajosos, que não refletem as características da síndrome de ornitofilia (Carvalho 1999).

A grande diversidade beta encontrada entre as áreas de Cerrado mais distantes e entre as fisionomias (Ratter et al. 2003; Bridgewater et al. 2004; Felfili et al. 2008) deve influenciar a diversidade e comportamento dos beija-flores em cada região em particular. Com plantas diferentes em cada área, eles devem utilizar uma maior variedade de recursos florais, inclusive de maneira oportunista, e devem depender da disponibilidade destes recursos (Maruyama et al. 2013). Isto tem sido comprovado nos poucos estudos sobre disponibilidade de recursos florais para beija- flores em áreas de Cerrado que envolveram diferentes fitofisionomias, onde algumas delas compartilharam recursos oferecidos ao beijaflores, mas também continham espécies exclusivas (Araújo et al. 2013; Maruyama et al. 2013).

O Cerrado apresenta plantas com flores ao longo do ano todo, apesar da sazonalidade marcada. No entanto, existem períodos onde a disponibilidade destes recursos pode ser mais baixa, não sendo uma determinada área ou fisionomia, suficiente para manter as populações residentes de beija-flores. Já é sabido que, em determinadas áreas, diferentes fisionomias se complementam na disponibilização de néctar, favorecendo a permanência deles na área (Araújo et al. 2013; Maruyama et al. 2013). Mas, não existem ainda para o Cerrado, estudos envolvendo áreas diferentes e mais distantes que permitam um melhor entendimento dos movimentos dos beijaflores numa escala regional.

Neste contexto, os objetivos do presente estudo foram determinar a riqueza de espécies vegetais utilizadas por beija-flores como fonte de néctar em áreas de cerrado s.r., caracterizar a distribuição temporal destes recursos e sua similaridade entre as áreas estudadas, além de determinar as espécies de beija-flores ocorrentes.

\section{Material e métodos}

Áreas de estudo

$\mathrm{O}$ estudo foi realizado em três áreas de preservação de Cerrado. Duas destas no Triângulo Mineiro, a RPPN do Clube de Caça e Pesca Itororó de Uberlândia (CCPIU) (18 $58^{\circ} \mathrm{S}-19^{\circ} 00^{\prime} \mathrm{S}$ e $\left.48^{\circ} 17^{\prime} \mathrm{O}-48^{\circ} 19^{\prime} \mathrm{O}\right)$ e a Estação Ecológica do Panga (EEP) (19 $09^{\prime} \mathrm{S}-19^{\circ} 11^{\prime} \mathrm{S}$ e $\left.48^{\circ} 23^{\prime} \mathrm{O}-48^{\circ} 24^{\prime} \mathrm{O}\right)$, e uma no sudeste de Goiás, o Parque Estadual da Serra de Caldas Novas (PESCAN) (17 $43^{\circ} \mathrm{S}-17^{\circ} 52^{\prime} \mathrm{S}$ e $48^{\circ} 39^{\prime} \mathrm{O}-48^{\circ} 45^{\prime} \mathrm{O}$ ) (Fig. 1).

As características climáticas da região de Uberlândia, onde se encontram o CCPIU e o Panga, e do sudeste de Goiás, localização do PESCAN, correspondem ao tipo Aw (segundo classificação de Köppen) com verão quente e úmido e inverno frio e seco. A temperatura anual média é de $22^{\circ} \mathrm{C}$ e a precipitação média é de $1.500 \mathrm{~mm}$ anuais, com chuvas concentradas entre os meses de outubro e março (Rosa et al. 1991; Nimer 1989).

A Estação Ecológica do Panga fica a uma distância aproximada de $21 \mathrm{~km}$ do Clube Caça e Pesca Itororó de Uberlândia. O Parque Estadual da Serra de Caldas Novas fica a cerca de $150 \mathrm{~km}$ da 
EEP e a cerca de $140 \mathrm{~km}$ do CCPIU. Em cada área de estudo foram delimitados dois transectos de $1.250 \mathrm{~m} \times 8 \mathrm{~m}$, sendo $4 \mathrm{~m}$ de cada lado da trilha, totalizando um hectare de área amostrada em cada transecto. Os transectos foram demarcados em áreas de cerrado (s.r.). A distância entre o final de um transecto e o início do outro foi de no mínimo 300 m e no máximo 1945 m (Fig. 1a-c).

\section{Coleta de dados}

As trilhas em cada transecto foram percorridas quinzenalmente no período de maio de 2009 a maio de 2010 e foram registradas todas as flores potencialmente utilizadas pelos beija-flores para consumo de néctar, tendo elas características ornitófilas ou não. Os critérios utilizados para inclusão das espécies foram a observação direta de visitas pelos beija-flores em campo e relatos de outros observadores e da literatura.

As plantas foram classificadas quanto ao hábito, coloração predominante da flor ou unidade de atração e forma da corola. Foram utilizadas as categorias de coloração descritas por Barbosa \& Sazima (2008): amarela, azul, branca, laranja, lilás, roxa e vermelha, sendo que flores com cores claras, próximas ao branco (baixa saturação, como esverdeado e creme) foram classificadas como branca. As flores foram ainda classificadas quanto à síndrome de polinização (sensu Faegri \& van der Pijl 1979) e foi observado de maneira geral o comportamento de floração das espécies vegetais. Foi observado o número de meses que as espécies apresentavam floração em cada uma das áreas de estudo, e as espécies foram classificadas como
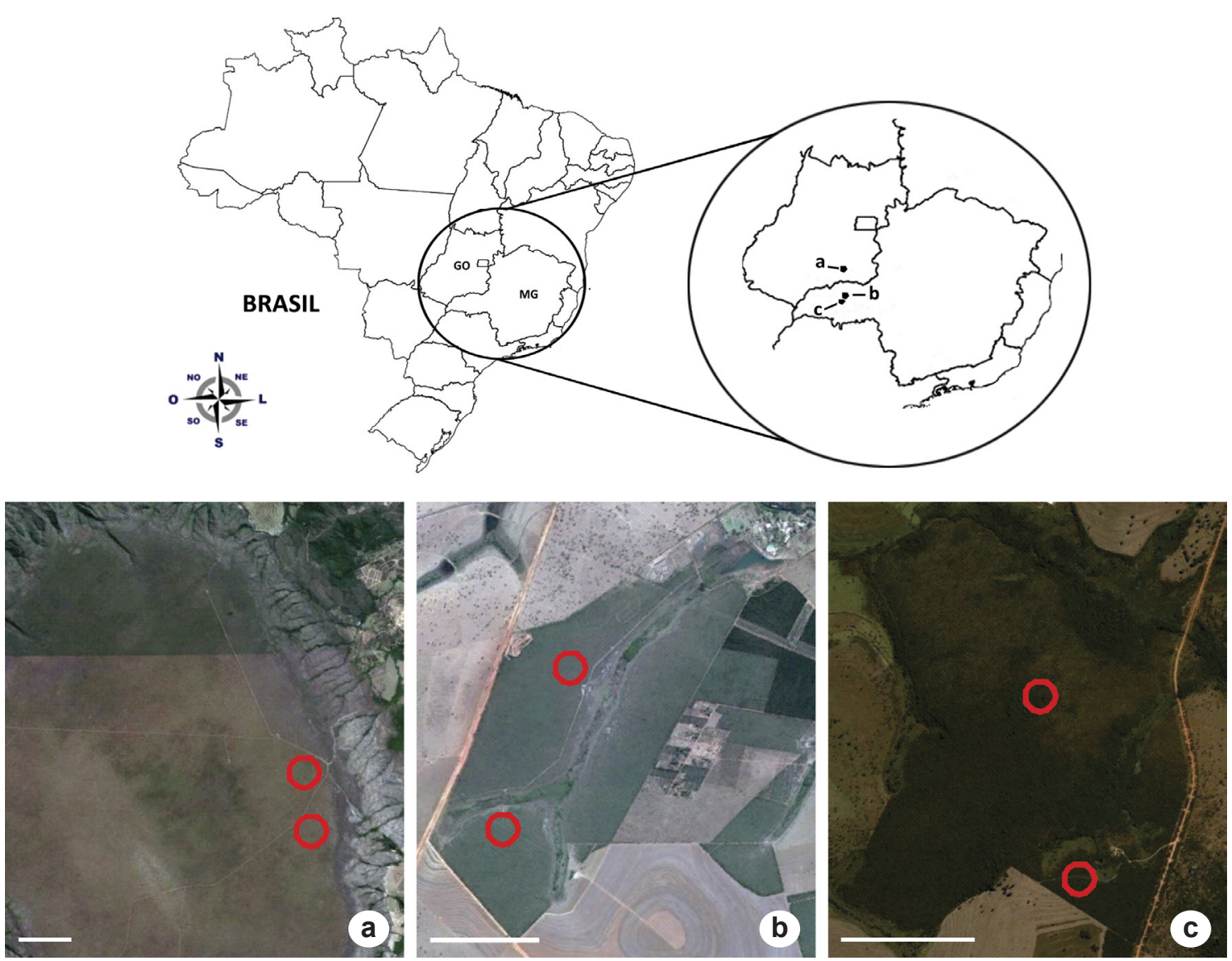

Figura 1 - Localização das áreas de estudo. a. Parque Estadual da Serra de Caldas Novas, Goiás (PESCAN). b. Clube de Caça e Pesca Itororó de Uberlândia, Uberlândia, Minas Gerais (CCPIU). c. Estação Ecológica do Panga, Uberlândia, Minas Gerais (EEP). Os círculos indicam as localizações dos transectos. Escala: 1.000 m. Fonte: Google Earth. Figure 1 - Location of the study areas. a. Parque Estadual da Serra de Caldas Novas, Goiás (PESCAN). b. Clube de Caça e Pesca Itororó de Uberlândia, Uberlândia, Minas Gerais (CCPIU). c. Estação Ecológica do Panga, Uberlândia, Minas Gerais (EEP). The circles indicate the transects location. Scale: 1,000 m. Source: Google Earth. 
de floração anual curta $(<1$ mês), intermediária ( 1 a 5 meses) ou estendida ( $>5$ meses) (adaptado de Newstrom et al. 1994; Araújo et al. 2013). Observações gerais nas áreas permitiram observar se o comportamento de floração se repetia em anos subsequentes, mas não foram realizadas observações plurianuais que permitissem definir padrões fenológicos. As áreas e os seus transectos foram comparados quanto à composição das espécies utilizadas pelos beija-flores através do coeficiente de Sørensen (Brower \& Zar 1984).

Para a determinação das espécies de beijaflores ocorrentes nas áreas de estudo foram feitas observações nos transectos demarcados e nas suas proximidades, com auxílio de binóculos e com registros fotográficos quando possível. Como as observações foram feitas concomitantemente ao percurso das trilhas, estima-se que foram feitas ca. 660 horas de observação (ca. 220 horas em cada área). A identificação dos beija-flores foi feita por meio de literatura (Grantsau 1989; Sigrist 2009) e auxílio de especialistas. Não se considerou o dimorfismo sexual dos beija-flores e estes só foram registrados quando visitavam especificamente as flores daquelas espécies de plantas incluídas no estudo.

\section{Resultados}

1 - Espécies de plantas

Caracterização

Durante o período de estudo, floresceram nas três áreas 26 espécies cujas flores ofereciam néctar como recurso alimentar aos beija-flores. Estas espécies estão distribuídas em 12 famílias e 21 gêneros (Tab. 1). As famílias com maior riqueza de espécies foram Vochysiaceae com seis espécies (23,1\%), Bignoniaceae com cinco (19,2\%) e Fabaceae com quatro $(15,4 \%)$. Bromeliaceae e Rubiaceae foram representadas por duas espécies cada, e as demais famílias por uma única espécie cada. Qualea foi o único gênero representado por três espécies, os gêneros Bauhinia, Palicourea e Vochysia por duas espécies e os demais gêneros por apenas uma espécie.

Entre as espécies registradas foi observada uma grande diversidade de cores predominantes no perianto. Predominaram as flores amarelas, com nove espécies $(34,6 \%)$, seguidas pela coloração branca com sete espécies (26,9\%). Três espécies apresentaram flores vermelhas e três roxas $(11,5 \%$ cada), duas espécies com corola laranja $(7,7 \%)$, e apenas uma azul e uma lilás (3,9\% cada). Cinco tipos florais foram registrados para as espécies estudadas. Os tipos goela e estandarte foram os mais frequentes (oito espécies cada - 30,8\%), seguidos pelas formas tubular (cinco espécies - 19,2\%), pincel (três espécies - 11,5\%) e taça (duas espécies - 7,7\%). Quanto ao hábito, a maioria das espécies $(12-46,1 \%)$ apresentou porte arbóreo, oito espécies apresentaram hábito subarbustivo $(30,8 \%)$ e cinco espécies foram herbáceas $(19,2 \%)$. Apenas uma espécie (3,9\%) apresentou hábito arbustivo (Tab. 1).

Dentre as 26 espécies registradas no estudo para as três áreas, nove $(34,6 \%)$ apresentaram características típicas da síndrome de ornitofilia (sensu Faegri \& van der Pijl 1979) (Tab. 1, Fig. 2). Das demais espécies registradas no estudo, 11 foram melitófilas, três quiropterófilas, duas esfingófilas e uma psicófila (Tab. 1, Fig. 3). Das famílias às quais pertencem as espécies tipicamente ornitófilas, Bromeliaceae e Rubiaceae foram as mais representativas com duas espécies cada (Tab. 1). Quanto à coloração das espécies ornitófilas, $33,3 \%$ delas apresentaram flores amarelas e 33,3\% vermelhas (três espécies cada), 22,2\% apresentaram cor laranja (duas espécies) e 11,1\% apresentou cor lilás (uma espécie). Ananas ananassoides tem ainda brácteas róseas vistosas e Palicourea rigida geralmente tem as hastes das inflorescências variando do laranja ao vinho. Algumas espécies mostraram variações na coloração das flores (ex. Alstroemeria sp., A. ananassoides e P. rigida) e como definido na metodologia, considerou-se a cor predominante no perianto. Com relação à forma da corola das espécies ornitófilas, a maioria $(55,5 \%)$ apresentou forma de tubo (cinco espécies), 33,3\% forma de goela (três) e 11,1\% de estandarte (uma). Em relação ao hábito das espécies ornitófilas, cinco $(55,5 \%)$ apresentaram porte herbáceo, três $(33,3 \%)$ subarbustivo e uma $(11,1 \%)$ arbustivo.

Similaridade entre os transectos eáreas

A área do PESCAN apresentou 22 espécies utilizadas como fonte de recurso pelos beija-flores, o Panga apresentou 19 e o CCPIU 17 espécies. Houve variação entre os transectos em cada área, mas a variação foi maior entre as áreas (Tab. 2). Seis espécies $(26,1 \%)$ ocorreram em apenas uma área de estudo, sendo o PESCAN a área que apresentou o maior número de espécies exclusivas (quatro).

Das 26 espécies registradas no estudo, 12 foram comuns às três áreas, o que corresponde a $46,1 \%$ das espécies. No entanto, somente cinco destas $(19,2 \%)$ ocorreram em todos os transectos de todas as áreas estudadas: Bowdichia virgilioides, 
Palicourea rigida, Styrax ferrugineus, Qualea grandiflora e Vochysia rufa (Tab. 2). A similaridade foi relativamente alta entre as áreas estudadas e também entre os transectos das mesmas, variando entre 71 e $87 \%$.
O número de espécies tipicamente ornitófilas foi maior na área do PESCAN, que apresentou oito das nove espécies registradas em todas as áreas $(88,9 \%)$. Já o CCPIU e a EEP apresentaram quatro espécies ornitófilas (44,4\% das ornitófilas)
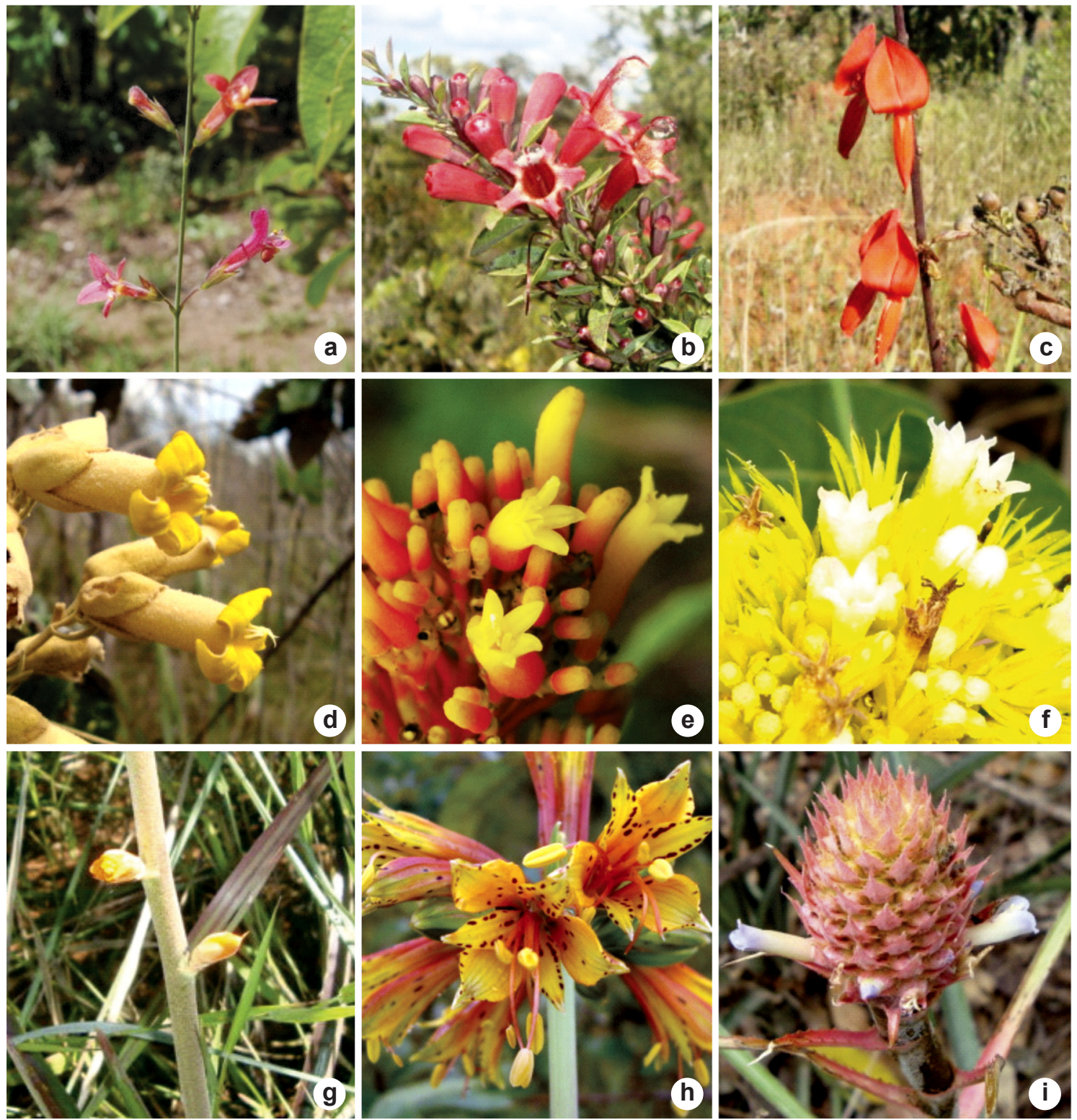

Figura 2 - Espécies ornitófilas registradas no cerrado do Parque Estadual da Serra de Caldas Novas, Goiás (PESCAN), do Clube de Caça e Pesca Itororó de Uberlândia (CCPIU), Uberlândia, Minas Gerais e da Estação Ecológica do Panga (EEP), Uberlândia, Minas Gerais. a. Hypenia cf. macrantha, b. Esterhazya splendida, c. Camptosema coriaceum, d. Zeyheria montana, e. Palicourea rigida, f. P. coriacea, g. Dyckia leptostachya, h. Alstroemeria sp., i. Ananas ananassoides. Figure 2 - Ornithophilous species recorded in the cerrado of the Parque Estadual da Serra de Caldas Novas, Goiás (PESCAN), of the Clube de Caça e Pesca Itororó de Uberlândia (CCPIU), Uberlândia, Minas Gerais and of the Estação Ecológica do Panga (EEP), Uberlândia, Minas Gerais. a. Hypenia cf. macrantha, b. Esterhazya splendida, c. Camptosema coriaceum, d. Zeyheria montana, e. Palicourea rigida, f. P. coriacea, g. Dyckia leptostachya, h. Alstroemeria sp., i. Ananas ananassoides. 
Tabela 1 - Características florais das espécies utilizadas pelos beija-flores no cerrado do Parque Estadual da Serra de Caldas Novas, Goiás (PESCAN), do Clube de Caça e Pesca Itororó de Uberlândia (CCPIU), Uberlândia, Minas Gerais e da Estação Ecológica do Panga (EEP), Uberlândia, Minas Gerais.

Table 1 - Floral features of species used by hummingbirds in the cerrado areas of the Serra de Caldas Novas' State Park, Goiás (PESCAN), Clube de Caça e Pesca Itororó de Uberlândia (CCPIU), Uberlândia, Minas Gerais and of the Panga Ecological Station (EEP), Uberlândia, Minas Gerais.

\begin{tabular}{|c|c|c|c|c|c|c|}
\hline Família / Espécie & $\begin{array}{l}\text { Cor da } \\
\text { corola }\end{array}$ & $\begin{array}{l}\text { Tipo } \\
\text { floral }^{\mathrm{a}}\end{array}$ & Hábito & $\begin{array}{l}\text { Padrão/ } \\
\text { frequência } \\
\text { floração }^{\text {b }}\end{array}$ & $\begin{array}{l}\text { Síndrome de } \\
\text { polinização }^{\mathrm{a}}\end{array}$ & $\begin{array}{c}\mathrm{N}^{\circ} \\
\text { registro } \\
\text { HUFU }\end{array}$ \\
\hline \multicolumn{7}{|l|}{ Alstroemeriaceae } \\
\hline Alstroemeria sp. * & Laranja & Tubo & Erva & $\begin{array}{c}\text { Anual/ } \\
\text { Intermediária }\end{array}$ & Ornitófila & - \\
\hline \multicolumn{7}{|l|}{ Bignoniaceae } \\
\hline $\begin{array}{l}\text { Adenocalymma campicola (Pilg.) L. } \\
\text { Lohmann }\end{array}$ & Amarela & Goela & Subarbusto & $\begin{array}{c}\text { Anual/ } \\
\text { Intermediária }\end{array}$ & Melitófila & 55499 \\
\hline Handroanthus ochraceus (Cham.) Mattos & Amarela & Goela & Árvore & $\begin{array}{c}\text { Anual/ } \\
\text { Intermediária }\end{array}$ & Melitófila & 55502 \\
\hline Jacaranda rufa Manso & Roxa & Goela & Subarbusto & $\begin{array}{c}\text { Anual/ } \\
\text { Intermediária }\end{array}$ & Melitófila & 46276 \\
\hline $\begin{array}{l}\text { Tabebuia aurea (Manso) Benth. \& Hook. } \\
\text { f. ex. S.Moore }\end{array}$ & Amarela & Goela & Árvore & $\begin{array}{l}\text { Anual/ } \\
\text { Intermediária }\end{array}$ & Melitófila & 55500 \\
\hline Zeyheria montana Mart. * & Amarela & Goela & Subarbusto & $\begin{array}{c}\text { Anual/ } \\
\text { Intermediária }\end{array}$ & Ornitófila & 47811 \\
\hline \multicolumn{7}{|l|}{ Bromeliaceae } \\
\hline Ananas ananassoides (Baker) L.B.Sm. * & Lilás & Tubo & Erva & $\begin{array}{c}\text { Anual/ } \\
\text { Intermediária }\end{array}$ & Ornitófila & 51988 \\
\hline Dyckia leptostachya Baker* & Laranja & Tubo & Erva & $\begin{array}{c}\text { Anual/ } \\
\text { Intermediária }\end{array}$ & Ornitófila & 51986 \\
\hline \multicolumn{7}{|l|}{ Bombacaceae } \\
\hline $\begin{array}{l}\text { Eriotheca gracilipes (K. Schum.) A. } \\
\text { Robyns }\end{array}$ & Branca & Taça & Árvore & $\begin{array}{c}\text { Anual/ } \\
\text { Intermediária }\end{array}$ & Melitófila & 51990 \\
\hline \multicolumn{7}{|l|}{ Caryocaraceae } \\
\hline Caryocar brasiliense Cambess. & Branca & Pincel & Árvore & $\begin{array}{c}\text { Anual/ } \\
\text { Intermediária }\end{array}$ & Quiropterófila & 55881 \\
\hline \multicolumn{7}{|l|}{ Fabaceae } \\
\hline Bauhinia brevipes Vogel & Branca & Pincel & Subarbusto & $\begin{array}{c}\text { Anual/ } \\
\text { Intermediária }\end{array}$ & Quiropterófila & 51892 \\
\hline Bauhinia ungulata $\mathrm{L}$. & Branca & Pincel & Subarbusto & $\begin{array}{c}\text { Anual/ } \\
\text { Intermediária }\end{array}$ & Quiropterófila & 51867 \\
\hline Bowdichia virgilioides Kunth. & Roxa & Estandarte & Árvore & $\begin{array}{c}\text { Anual/ } \\
\text { Intermediária }\end{array}$ & Melitófila & 51865 \\
\hline Camptosema coriaceum Benth. * & Vermelha & Estandarte & Erva & $\begin{array}{l}\text { Anual/ } \\
\text { Estendida }\end{array}$ & Ornitófila & 51985 \\
\hline \multicolumn{7}{|l|}{ Lamiaceae } \\
\hline Hypenia cf. macrantha (Benth.) Harley* & Vermelha & Goela & Erva & $\begin{array}{l}\text { Anual/ } \\
\text { Estendida }\end{array}$ & Ornitófila & - \\
\hline \multicolumn{7}{|l|}{ Orobanchaceae } \\
\hline Esterhazya splendida Mikan * & Vermelha & Goela & Subarbusto & $\begin{array}{c}\text { Anual/ } \\
\text { Intermediária }\end{array}$ & Ornitófila & - \\
\hline \multicolumn{7}{|l|}{ Rubiaceae } \\
\hline Palicourea coriacea Schum. * & Amarela & Tubo & Subarbusto & $\begin{array}{l}\text { Anual/ } \\
\text { Estendida }\end{array}$ & Ornitófila & 60894 \\
\hline
\end{tabular}




\begin{tabular}{|c|c|c|c|c|c|c|}
\hline Família Espécie & $\begin{array}{l}\text { Cor da } \\
\text { corola }\end{array}$ & $\begin{array}{l}\text { Tipo } \\
\text { floral }^{\mathrm{a}}\end{array}$ & Hábito & $\begin{array}{c}\text { Padrão/ } \\
\text { frequência } \\
\text { floração }^{b}\end{array}$ & $\begin{array}{l}\text { Síndrome de } \\
\text { polinização }^{\mathrm{a}}\end{array}$ & $\begin{array}{c}\quad \mathrm{N}^{\circ} \\
\text { registro } \\
\text { HUFU }\end{array}$ \\
\hline Palicourea rigida H. B. \& K. * & Amarela & Tubo & $\begin{array}{l}\text { Arbusto/ } \\
\text { Arvoreta }\end{array}$ & $\begin{array}{l}\text { Anual/ } \\
\text { Estendida }\end{array}$ & Ornitófila & 60893 \\
\hline \multicolumn{7}{|l|}{ Styracaceae } \\
\hline Styrax ferrugineus Nees \& Mart. & Branca & Taça & Árvore & $\begin{array}{c}\text { Anual/ } \\
\text { Estendida }\end{array}$ & Melitófila & 51864 \\
\hline \multicolumn{7}{|l|}{ Verbenaceae } \\
\hline Stachytarpheta gesnerioides Cham. & Azul & Goela & Subarbusto & $\begin{array}{c}\text { Anual/ } \\
\text { Intermediária }\end{array}$ & Psicófila & 51878 \\
\hline \multicolumn{7}{|l|}{ Vochysiaceae } \\
\hline Qualea grandiflora Mart. & Amarela & Estandarte & Árvore & $\begin{array}{c}\text { Anual/ } \\
\text { Intermediária }\end{array}$ & Esfingófila & 60895 \\
\hline Qualea multiflora Mart. & Branca & Estandarte & Árvore & $\begin{array}{c}\text { Anual/ } \\
\text { Estendida }\end{array}$ & Melitófila & 51859 \\
\hline Qualea parviflora Mart. & Roxa & Estandarte & Árvore & $\begin{array}{c}\text { Anual/ } \\
\text { Intermediária }\end{array}$ & Melitófila & 60896 \\
\hline Salvertia convallariaeodora A. St. Hil. & Branca & Estandarte & Árvore & $\begin{array}{c}\text { Anual/ } \\
\text { Intermediária }\end{array}$ & Esfingófila & 51989 \\
\hline Vochysia cinnamomea Pohl. & Amarela & Estandarte & Árvore & $\begin{array}{c}\text { Anual/ } \\
\text { Intermediária }\end{array}$ & Melitófila & - \\
\hline Vochysia rufa Mart. & Amarela & Estandarte & Árvore & $\begin{array}{c}\text { Anual/ } \\
\text { Intermediária }\end{array}$ & Melitófila & 47810 \\
\hline
\end{tabular}

Símbolos: * = Espécies ornitófilas; a = sensu Faegri \& van der Pij1 1979; b = sensu Newstrom et al. 1994.

(Tab. 2). A similaridade entre as áreas quanto às espécies ornitófilas foi de 50,0\% para comparações feitas entre quaisquer duas áreas. Analisando-se cada área, os transectos do CCPIU tiveram 100\% de similaridade quanto às espécies ornitófilas e, tanto os transectos do PESCAN como os da EEP foram $67,0 \%$ similares. A única espécie ornitófila que ocorreu em todas as áreas e transectos foi $P$. rigida (Tab. 2).

\section{Fenologia}

O comportamento fenológico de todas as espécies nas três áreas, durante o estudo foi anual (com um ciclo principal de floração durante o ano de estudo, sensu Newstrom et al. 1994). A organização das espécies em ordem de mês de início de floração sugere uma sequência temporal de floração, embora isso não tenha sido testado estatisticamente e tenha havido ampla sobreposição entre espécies. Quanto à duração da floração, a maioria $(76,9 \%)$ foi intermediária variando de um a cinco meses, e $23,1 \%$ apresentaram duração estendida, florescendo por seis meses ou mais (Tab. 1, Fig. 4, 5, 6). Quanto ao padrão e duração de floração das espécies ornitófilas, cinco $(55,5 \%)$ espécies tiveram floração anual intermediária e quatro $(44,4 \%)$ tiveram floração anual estendida (Tab. 1).

A maioria das espécies $(50,0 \%)$ teve floração apenas na estação seca enquanto que $38,5 \%$ floresceram somente durante a estação chuvosa. Apenas três espécies (11,5\%) tiveram eventos de floração durante as duas estações em igual duração, no entanto, somente Camptosema coriaceum floresceu abundantemente nas duas estações do ano em todas as áreas e transectos onde ocorreu (Fig. 4, 5). Ananas ananassoides floresceu entre as estações seca e chuvosa em todos os transectos onde ocorreu (Figura 5,6) e Alstroemeria sp. floresceu no período de transição entre as estações chuvosa e seca (Fig. 4).

Em todas as áreas de estudo, houve espécies (ornitófilas e/ou não ornitófilas) florescendo em todos os meses do período estudado (Fig. $4,5,6$ ), com uma média de 7,08 espécies por mês no PESCAN; 5,31 no CCPIU e 5,23 no Panga. Considerando-se as três áreas de estudo conjuntamente, houve uma média de 11,2 espécies florescendo ao mês (Fig. 7). O mês de julho de 2009 foi o que apresentou o maior número de 
espécies florescendo (17 spp. - 65,4\% do total registrado nas três áreas de estudo), seguido pelos meses de junho e maio do mesmo ano, 15 e 14 espécies respectivamente. Já os meses de dezembro e novembro foram os que tiveram menor número de espécies floridas (sete e oito respectivamente), ou seja, menos de um terço do total de espécies. Considerando-se somente as
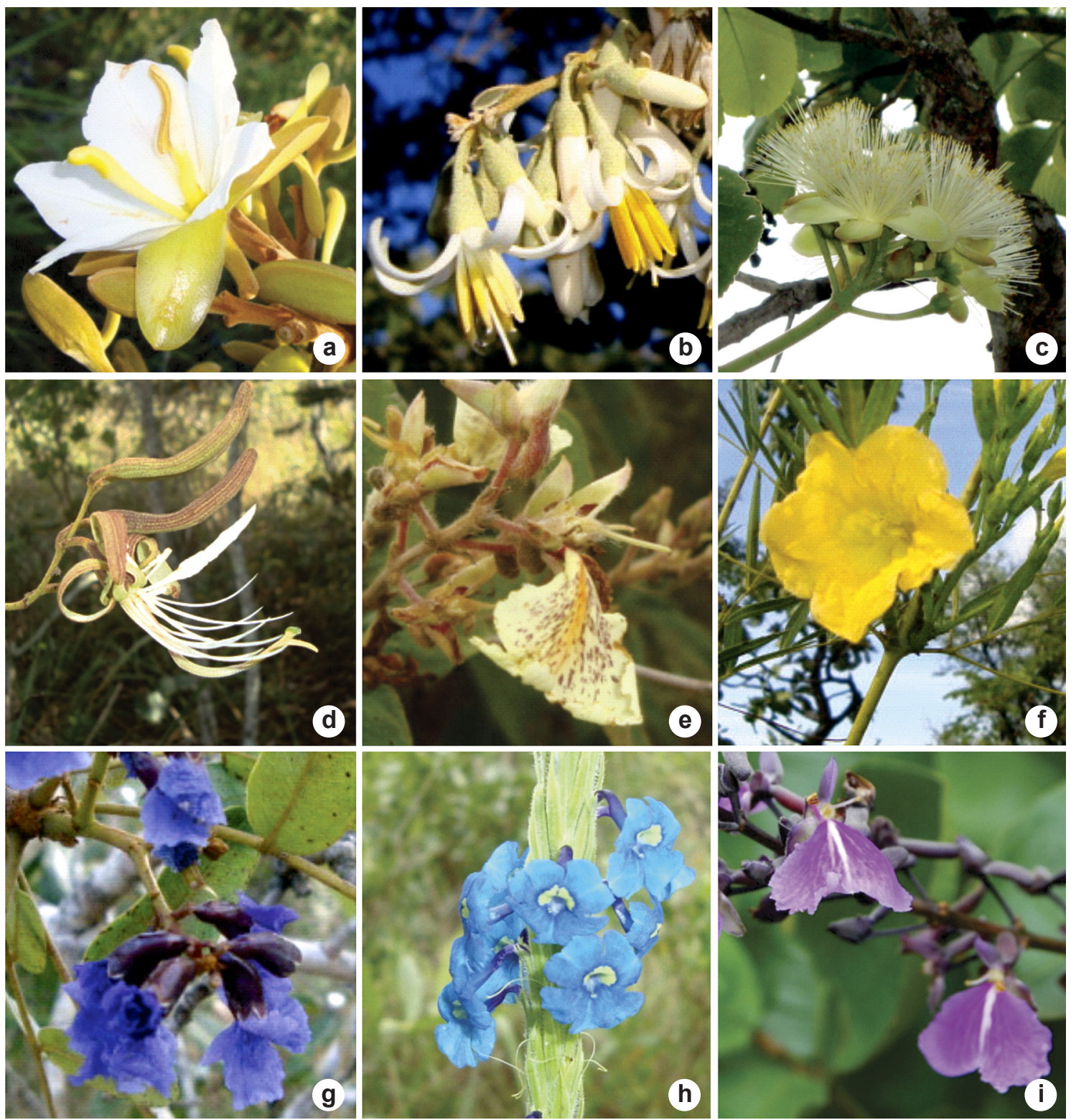

Figura 3 - Espécies não ornitófilas potencialmente utilizadas por beija-flores registradas no cerrado do Parque Estadual da Serra de Caldas Novas, Goiás (PESCAN), do Clube de Caça e Pesca Itororó de Uberlândia (CCPIU), Uberlândia, Minas Gerais e da Estação Ecológica do Panga (EEP), Uberlândia, Minas Gerais. a. Salvertia convallariaeodora, b. Styrax ferrugineus, c. Caryocar brasiliense, d: Bauhinia ungulata, e. Qualea multiflora, f. Adenocalymma campicola, g. Bowdichia virgilioides, h. Stachytarpheta gesnerioides, i. Qualea parviflora.

Figure 3 - Non-ornithophilous species recorded in the cerrado of the Parque Estadual da Serra de Caldas Novas, Goiás (PESCAN), of the Clube de Caça e Pesca Itororó de Uberlândia (CCPIU), Uberlândia, Minas Gerais and of the Estação Ecológica do Panga (EEP), Uberlândia, Minas Gerais. a. Salvertia convallariaeodora, b. Styrax ferrugineus, c. Caryocar brasiliense, d. Bauhinia ungulata, e. Qualea multiflora, f. Adenocalymma campicola, g. Bowdichia virgilioides, h. Stachytarpheta gesnerioides, i. Qualea parviflora. 
Tabela 2 - Vinte e seis espécies utilizadas por beija-flores para obtenção de recurso floral e suas ocorrências nas áreas de cerrado do Parque Estadual da Serra de Caldas Novas, Goiás (PESCAN), do Clube de Caça e Pesca Itororó de Uberlândia (CCPIU), Uberlândia, Minas Gerais e da Estação Ecológica do Panga (EEP), Uberlândia, Minas Gerais. T = transecto. Table 2 - Twenty-six plant species used by hummingbirds as floral resources and their occurrence in the cerrado areas of the Serra de Caldas Novas State Park, Goiás (PESCAN), of the Clube de Caça e Pesca Itororó de Uberlândia (CCPIU), Uberlândia, Minas Gerais and of the Panga Ecological Station (EEP), Uberlândia, Minas Gerais. T: transect.

\begin{tabular}{|c|c|c|c|c|c|c|}
\hline \multirow[b]{3}{*}{ Família / Espécie } & \multicolumn{6}{|c|}{ Áreas } \\
\hline & \multicolumn{2}{|c|}{ PESCAN } & \multicolumn{2}{|c|}{ CCPIU } & \multicolumn{2}{|c|}{ PANGA } \\
\hline & T 1 & T 2 & T 1 & T 2 & T 1 & T 2 \\
\hline \multicolumn{7}{|l|}{ Alstroemeriaceae } \\
\hline Alstroemeria sp. * & & $\mathrm{X}$ & & & & \\
\hline \multicolumn{7}{|l|}{ Bignoniaceae } \\
\hline Adenocalymma campicola & $\mathrm{X}$ & $\mathrm{X}$ & $\mathrm{X}$ & $\mathrm{X}$ & $\mathrm{X}$ & \\
\hline Handroanthus ochraceous & & $\mathrm{X}$ & & & & \\
\hline Jacaranda rufa & & & $\mathrm{x}$ & & & \\
\hline Tabebuia aurea & $\mathrm{x}$ & $\mathrm{x}$ & & $\mathrm{x}$ & $\mathrm{x}$ & \\
\hline Zeyheria montana * & $\mathrm{x}$ & & & & $\mathrm{x}$ & \\
\hline \multicolumn{7}{|l|}{ Bromeliaceae } \\
\hline Ananas ananassoides * & & & $\mathrm{x}$ & $\mathrm{x}$ & $\mathrm{x}$ & $\mathrm{x}$ \\
\hline Dyckia leptostachya * & $\mathrm{x}$ & $\mathrm{x}$ & & & $\mathrm{x}$ & \\
\hline \multicolumn{7}{|l|}{ Caryocaraceae } \\
\hline Caryocar brasiliense & $\mathrm{x}$ & & $\mathrm{x}$ & $\mathrm{x}$ & $\mathrm{x}$ & $\mathrm{x}$ \\
\hline \multicolumn{7}{|l|}{ Fabaceae } \\
\hline Bauhinia brevipes & $\mathrm{x}$ & $\mathrm{x}$ & $\mathrm{x}$ & & $\mathrm{x}$ & $\mathrm{x}$ \\
\hline Bauhinia ungulata & $\mathrm{x}$ & & & & $\mathrm{x}$ & \\
\hline Bowdichia virgilioides & $\mathrm{x}$ & $\mathrm{x}$ & $\mathrm{x}$ & $\mathrm{x}$ & $\mathrm{x}$ & $\mathrm{x}$ \\
\hline Camptosema coriaceum $*$ & $\mathrm{x}$ & $\mathrm{x}$ & $\mathrm{x}$ & $\mathrm{x}$ & & \\
\hline \multicolumn{7}{|l|}{ Lamiaceae } \\
\hline Hypenia cf. macranta * & $\mathrm{x}$ & & & & & \\
\hline \multicolumn{7}{|l|}{ Malvaceae } \\
\hline Eriotheca gracilipes & & & $\mathrm{x}$ & $\mathrm{x}$ & $\mathrm{x}$ & $\mathrm{x}$ \\
\hline \multicolumn{7}{|l|}{ Orobancaceae } \\
\hline Esterhazya splendida * & $\mathrm{x}$ & & $\mathrm{x}$ & $\mathrm{x}$ & & \\
\hline \multicolumn{7}{|l|}{ Rubiaceae } \\
\hline Palicourea coriacea $*$ & $\mathrm{x}$ & $\mathrm{x}$ & & & & \\
\hline Palicourea rigida $*$ & $\mathrm{X}$ & $\mathrm{x}$ & $\mathrm{x}$ & $\mathrm{x}$ & $\mathrm{X}$ & $\mathrm{X}$ \\
\hline \multicolumn{7}{|l|}{ Styracaceae } \\
\hline Styrax ferrugineus & $\mathrm{x}$ & $\mathrm{x}$ & $\mathrm{x}$ & $\mathrm{x}$ & $\mathrm{x}$ & $\mathrm{x}$ \\
\hline \multicolumn{7}{|l|}{ Verbenaceae } \\
\hline Stachytarpheta gesnerioides & & & & & $\mathrm{x}$ & \\
\hline \multicolumn{7}{|l|}{ Vochysiaceae } \\
\hline Qualea grandiflora & $\mathrm{X}$ & $\mathrm{X}$ & $\mathrm{X}$ & $\mathrm{X}$ & $\mathrm{X}$ & $\mathrm{X}$ \\
\hline Qualea multiflora & $\mathrm{x}$ & $\mathrm{x}$ & $\mathrm{x}$ & $\mathrm{x}$ & & $\mathrm{x}$ \\
\hline
\end{tabular}




\begin{tabular}{|c|c|c|c|c|c|c|}
\hline \multirow[b]{3}{*}{ Família / Espécie } & \multicolumn{6}{|c|}{ Áreas } \\
\hline & \multicolumn{2}{|c|}{ PESCAN } & \multicolumn{2}{|c|}{ CCPIU } & \multicolumn{2}{|c|}{ PANGA } \\
\hline & T 1 & T 2 & T 1 & T 2 & T 1 & T 2 \\
\hline Qualea parviflora & $\mathrm{x}$ & & $\mathrm{X}$ & $\mathrm{X}$ & $\mathrm{x}$ & $\mathrm{x}$ \\
\hline Salvertia convallariaeodora & $\mathrm{X}$ & & & & & $\mathrm{X}$ \\
\hline Vochysia cinammomea & & $\mathrm{X}$ & $\mathrm{X}$ & & $\mathrm{X}$ & $\mathrm{X}$ \\
\hline Vochysia rufa & $\mathrm{x}$ & $\mathrm{X}$ & $\mathrm{x}$ & $\mathrm{x}$ & $\mathrm{x}$ & $\mathrm{x}$ \\
\hline
\end{tabular}

espécies ornitófilas, uma média de 4,85 espécies floresceu ao mês, sendo que o maior número de espécies ornitófilas floresceu durante o mês de junho de 2009 (sete espécies - 77,7\%), e o menor número foi observado no mês de novembro (duas espécies - 22,2\%). Na maioria dos meses estudados, o número de espécies não ornitófilas floridas foi maior que o de espécies ornitófilas. A exceção ocorreu apenas nos meses de setembro e dezembro de 2009 (Fig. 7). Considerando-se as áreas separadamente, somente na área do Panga não houve espécies ornitófilas florescendo em três meses do período de estudo (junho e julho/2009 e fevereiro/2010) (Fig. 6).

\section{2 - Beija-flores}

Durante o período de estudo foram registradas nove espécies de beija-flores nas três áreas, todos da subfamília Trochilinae, Amazilia fimbriata (Gmelin, 1788), Calliphlox amethystina (Boddaert 1783), Chrysolampis mosquitus (Linnaeus 1758), Chlorostilbon lucidus (Shaw 1812), Colibri serrirostris (Vieillot 1816), Eupetomena macroura (Gmelin 1788), Heliactin bilophus (Temminck 1820), Lophornis magnificus (Vieillot 1817) e Thalurania furcata (Gmelin 1788).

$\mathrm{O}$ número total de avistamentos de beijaflores nas três áreas durante o período de estudo foi 178 (média de 2,18 avistamentos ao dia). No PESCAN foram 72 registros de beija-flores nos 27 dias investigados naquela área (2,66/dia), no CCPIU foram 28 (1,04/dia) e no Panga 78 (2,89/dia). O período entre os meses de maio e julho/09, e entre outubro/09 e dezembro/10 foram os que tiveram maior número de registros de beija-flores, sendo o mês de novembro o que teve o maior número nas três áreas (49) seguido pelo mês de junho/09 (32). Em agosto/09 e janeiro/10 foram observadas menos visitas por beija-flores, e em setembro/09 e fevereiro/10 não houve nenhum registro de visita.

\section{Discussão}

O número de espécies vegetais registrado neste estudo como possíveis recursos alimentares utilizados por beija-flores é comparável ao de outros estudos realizados na região, desde que consideradas as mesmas áreas ou fisionomias. $\mathrm{O}$ fato é que nenhum trabalho havia sido feito anteriormente em uma escala mais ampla (i.e., regional). Os estudos anteriores se concentraram numa única área e comumente incluíram fisionomias de mata e campo sujo além de cerrado s.r. (e.g. Araújo et al. 2013; Maruyama et al. 2013). $\mathrm{O}$ número de espécies registrado aqui (26) foi semelhante ao encontrado noutro estudo realizado na Estação Ecológica do Panga, considerando-se apenas o registrado para cerrado e campo sujo (29 spp.) já que tal estudo envolveu também formações florestais (Araújo et al. 2013). Outro estudo feito nesta mesma área, também envolvendo fisionomias de mata, revelou número menor de espécies no campo sujo (12), embora este trabalho tenha sido feito em área bem menor (menos de 0,5 ha) (Maruyama et al. 2013). Cabe ressaltar ainda que este último trabalho foi feito em uma área que coincide em parte com um dos transectos do presente estudo, que era então considerada como campo sujo (Schiavini \& Araújo 1989). Esta área foi reavaliada após 18 anos e devido às mudanças na estrutura e composição florística, é atualmente considerada como um mosaico de cerrado ralo e cerrado típico, subgrupos de cerrado sentido restrito (ver Cardoso et al. 2009).

Em um trabalho realizado na RPPN do Clube de Caça e Pesca Itororó de Uberlândia, o número de espécies encontrado foi menor (nove spp.) (Maruyama et al. 2013). Mesmo que este trabalho tenha sido feito em apenas $1 \mathrm{ha}$, o que corresponde à metade da área do presente estudo, ainda assim o número foi menor, pois o transecto que apresentou menos espécies no CCPIU continha 14 spp. Além 


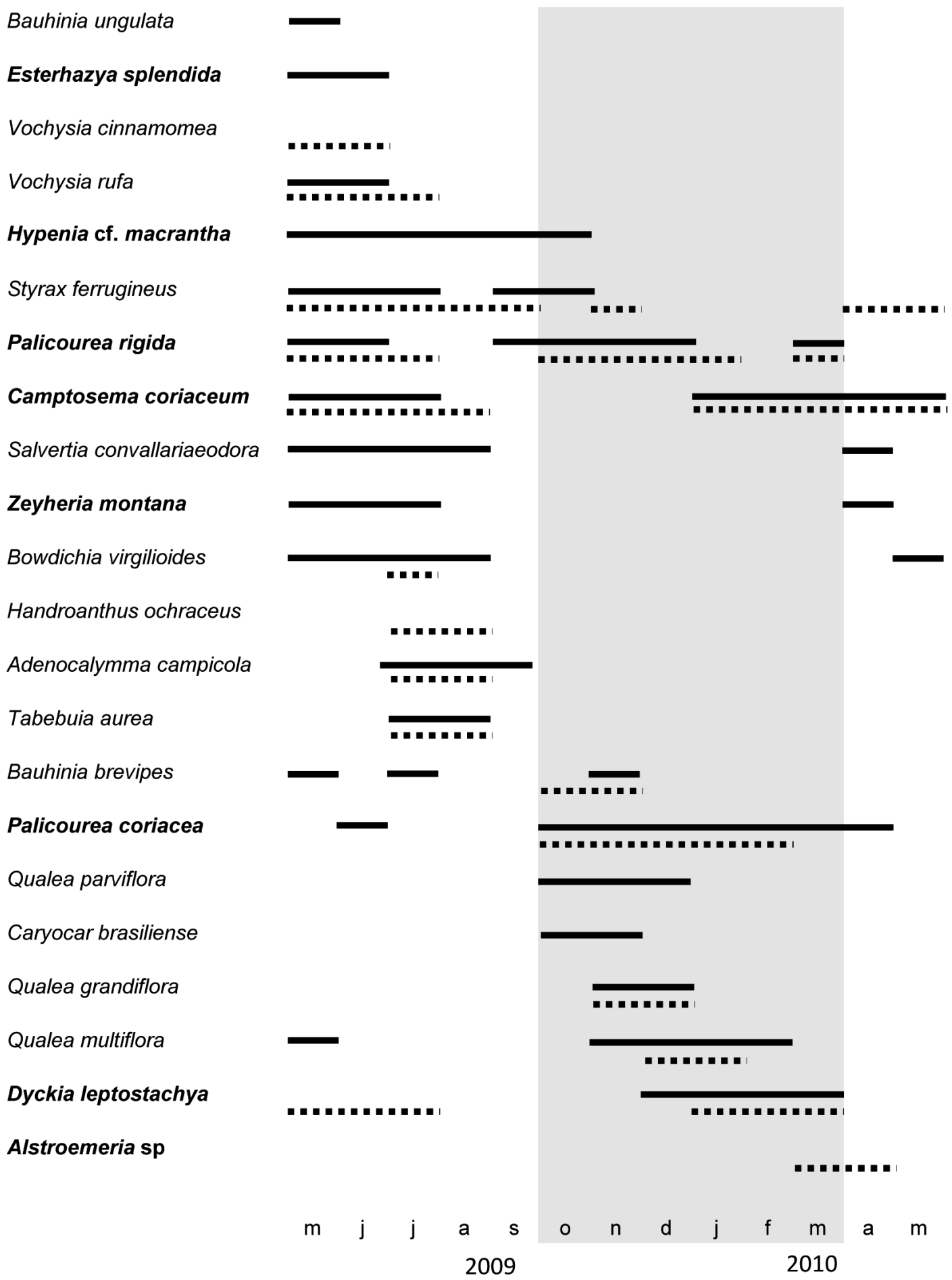

Figura 4 - Fenologia de floração das espécies utilizadas por beija-flores no cerrado do Parque Estadual da Serra de Caldas Novas, Goiás (PESCAN). Linhas contínuas: transecto 1 e linhas tracejadas: transecto 2. Negrito: espécies ornitófilas. Faixa sombreada: período chuvoso.

Figure 4 - Flowering phenology of the species used by hummingbirds in the cerrado of the Parque Estadual da Serra de Caldas Novas, Goiás (PESCAN). Solid lines: transect 1 and dashed lines: transect 2. Bold: ornithophilous species. Shaded band: rainy season. 
disso, todas as espécies registradas em tal trabalho foram registradas neste.

A guilda de plantas utilizada por beijaflores nos cerrados da região certamente é maior do que a amostrada no presente estudo, já que algumas espécies, como Bromelia balansae Mez no PESCAN e Amasonia hirta Benth. no Panga, não foram registradas por não terem tido eventos de floração dentro do transecto durante o período de estudo. E ainda, outras espécies como Bauhinia holophylla (Bong.) Steud., B. rufa (Bong.) Steud.,
Helicteres brevispira A.St.-Hil., Camptosema coriaceum (Nees \& Mart.) Benth. e duas espécies de Hyptis foram registradas em outros estudos no Panga, mas não neste (Araújo et al. 2013; Maruyama et al. 2013).

O número de espécies de plantas registrado aqui foi semelhante ao de outros ambientes como Caatinga (Machado 2009), florestas tropicais secas (Arizmendi \& Ornelas 1990) e capões do Pantanal (Araújo \& Sazima 2003). No entanto, em campos rupestres, com fisionomia mais aberta

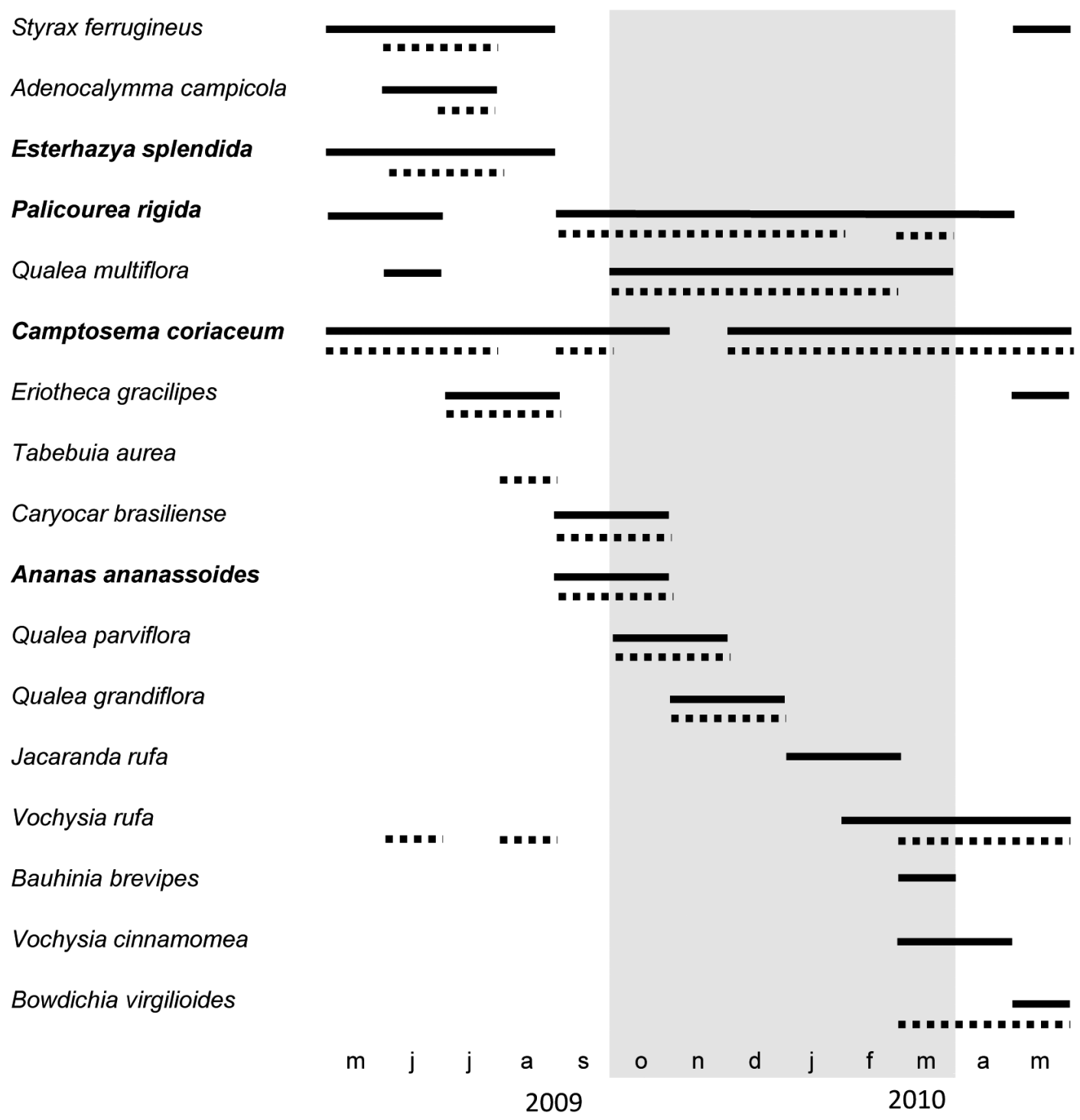

Figura 5 - Fenologia de floração das espécies utilizadas por beija-flores no cerrado do Clube de Caça e Pesca Itororó de Uberlândia (CCPIU), Uberlândia, Minas Gerais. Linhas contínuas: transecto 1 e linhas tracejadas: transecto 2. Negrito: espécies ornitófilas. Faixa sombreada: período chuvoso.

Figure 5 - Flowering phenology of the species used by hummingbirds in the cerrado of the Clube de Caça e Pesca Itororó de Uberlândia (CCPIU), Uberlândia, Minas Gerais. Solid lines: transect 1 and dashed lines: transect 2. Bold: ornithophilous species. Shaded band: rainy season. 
à semelhança do cerrado, houve maior número de espécies visitadas por beija-flores (Vasconcelos \& Lombardi 2001; Machado et al. 2007; Rodrigues 2011).

Quando comparamos a riqueza de espécies da flora utilizada por beija-flores no cerrado com ambientes de florestas tropicais úmidas, os números encontrados no presente estudo se mostraram marcadamente menores. Estudos realizados em florestas tropicais com maiores índices pluviométricos e, sobretudo, com chuvas mais uniformemente distribuídas, como Floresta Amazônica Colombiana (Lasprilla \& Sazima 2004), Florestas Tropicais da Costa Rica (Stiles

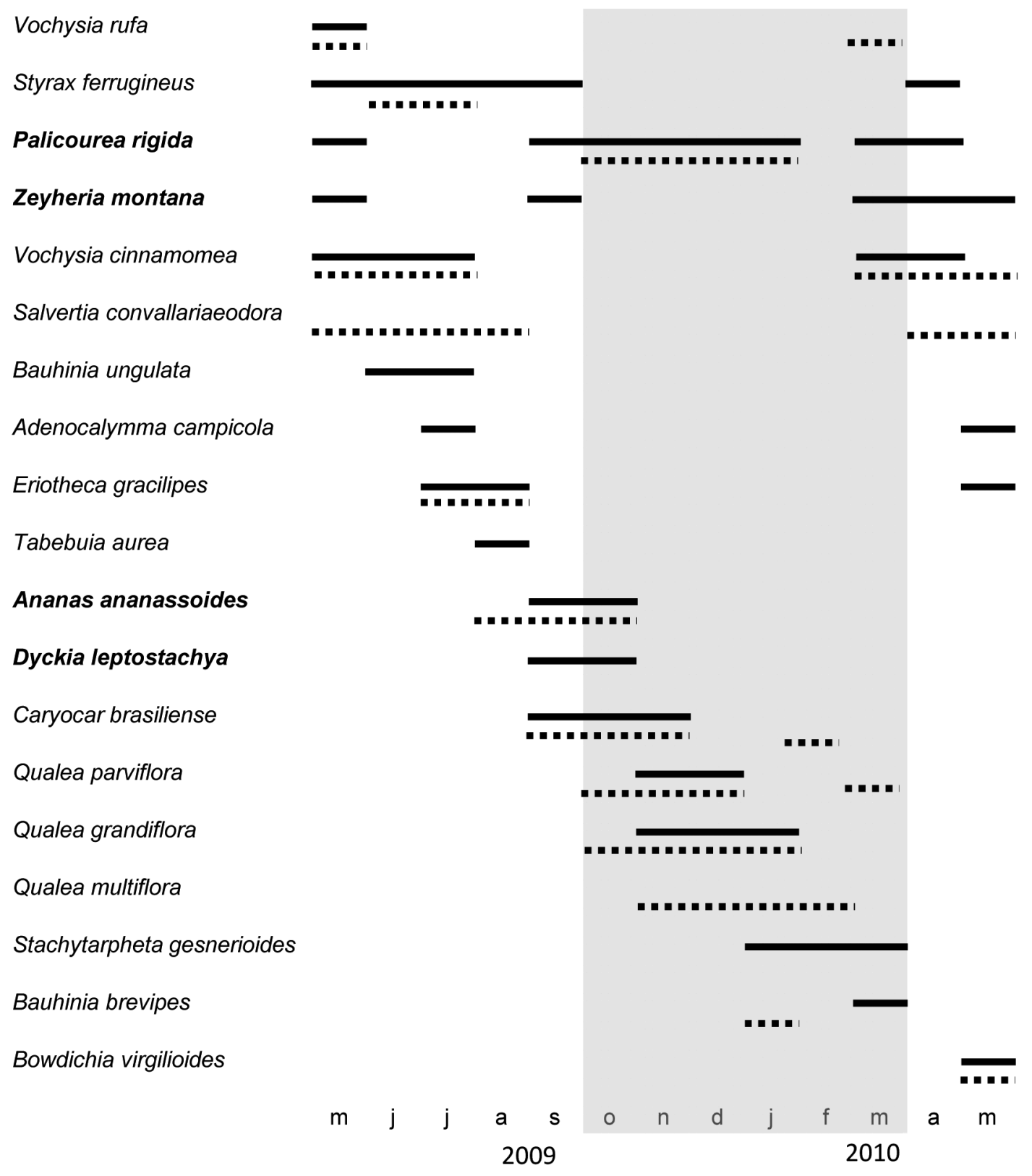

Figura 6 - Fenologia de floração das espécies utilizadas por beija-flores no cerrado da Estação Ecológica do Panga (EEP), Uberlândia, Minas Gerais. Linhas contínuas: transecto 1 e linhas tracejadas: transecto 2. Negrito: espécies ornitófilas. Faixa sombreada: período chuvoso.

Figure 6 - Flowering phenology of the species used by hummingbirds in the cerrado of the Estação Ecológica do Panga (EEP), Uberlândia, Minas Gerais. Solid lines: transect 1 and dashed lines: transect 2. Bold: ornithophilous species. Shaded band: rainy season. 


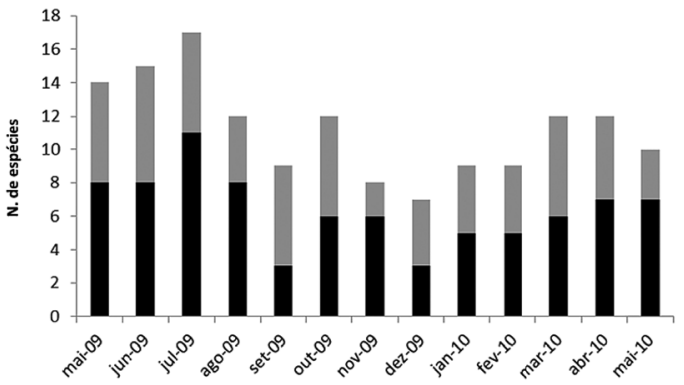

Figura 7 - Número de espécies utilizadas por beijaflores floridas durante o período do estudo no cerrado do Parque Estadual da Serra de Caldas Novas, Goiás (PESCAN), do Clube de Caça e Pesca Itororó de Uberlândia (CCPIU), Uberlândia, Minas Gerais e da Estação Ecológica do Panga (EEP), Uberlândia, Minas Gerais. Barras pretas: espécies não ornitófilas, barras cinza: espécies ornitófilas.

Figure 7 - Number of the species used by hummingbirds flowering during the study period in the cerrado of the Parque Estadual da Serra de Caldas Novas, Goiás (PESCAN), of the Clube de Caça e Pesca Itororó de Uberlândia (CCPIU), Uberlândia, Minas Gerais and of the Estação Ecológica do Panga (EEP), Uberlândia, Minas Gerais. Black bars: non-ornithophilous species, gray bars: ornithophilous species.

1978), Floresta Tropical Montanhosa do Equador (Dziedzioch et al. 2003) e Mata Atlântica Brasileira (Araújo 1996; Buzato et al. 2000; Canela 2006; Rocca-de-Andrade 2006) geralmente indicam uma maior riqueza de espécies vegetais sendo visitadas/polinizadas por beija-flores. Além disso, a proporção de espécies tipicamente ornitófilas nestes ambientes em relação à assembleia de flores encontrada comumente é maior (Araújo 1996; Rocca-de-Andrade 2006). As espécies ornitófilas representaram pouco mais de $30 \%$ do total de espécies visitadas por beija-flores no presente estudo, e em torno de $40 \%$ para os estudos em cerrado da região (Araújo et al. 2013; Maruyama et al. 2013). É possível que a menor riqueza de grupos tipicamente ornitófilos, como Bromeliaceae e Acanthaceae, em áreas abertas de Cerrado expliquem tais diferenças (Ferreira et al. [inédito]).

As famílias Bignoniaceae, Fabaceae e Vochysiaceae somaram juntas quase $60 \%$ de todas as espécies registradas. Em outro estudo com a mesma abordagem feito na Estação Ecológica do Panga, estas famílias estiveram entre as mais representativas (Araújo et al. 2013) e no CCPIU, Vochysiaceae foi a única família representada por mais de uma espécie (Maruyama et al. 2013). Isto se deve certamente ao fato de que estas famílias estão entre as mais representativas do Cerrado do Triângulo Mineiro e sudeste de Goiás (Faleiro 2007; Costa \& Araújo 2001; Silva et al. 2002; Carvalho et al. 2008; Lopes et al. 2011), assim como na maioria das áreas de cerrado (Ratter et al. 2003). Até mesmo em outros ambientes como os capões do Pantanal, as três famílias citadas acima foram as mais importantes da flora visitada por beija-flores (Araújo \& Sazima 2003). Por exemplo, Qualea grandiflora, presente em todas as áreas e transectos estudados aqui, é a espécie mais difundida no cerrado brasileiro (Ratter et al. 2003; Lopes et al. 2011).

Com exceção de algumas famílias mais importantes em determinados ambientes, como Bromeliaceae em Mata Atlântica, em floras polinizadas por beija-flores é mais comum haver famílias e gêneros com poucas espécies (uma ou duas) (Sazima et al. 1996; Arizmendi \& Ornelas 1990; Buzato et al. 2000; Vasconcelos \& Lombardi 2001; Lopes 2002; Abreu \& Vieira 2004; Lasprilla \& Sazima 2004; Canela 2006; Dalsgaard et al. 2009; Machado 2009; Araújo et al. 2011; Araújo et al. 2013; Maruyama et al. 2013). Esta grande diversidade de famílias e gêneros das guildas de plantas polinizadas por beija-flores tem sido vista como resultado de uma coevolução difusa, que resultou em um padrão de interação mais generalista entre plantas e aves (Buzato et al. 2000). No entanto, as ideias mais aceitas atualmente para organização de comunidades envolvem mecanismos de dispersão, filtragem ambiental e interações competitivas e facilitadoras, que fornecem possibilidades de predições muito mais factíveis de teste que a ideia de coevolução difusa. Por exemplo, o grande número de famílias com poucas espécies sugere dispersão filogenética e convergência fenotípica (Sargent \& Ackerly 2008) que são esperados em situações de organização de comunidades direcionadas por competição e baixa conservação de atributos florais.

Em florestas neotropicais, grande parte das flores visitadas por beija-flores possuem características relacionadas à síndrome de ornitofilia, como coloração tendendo ao vermelho e forma tubular (Araújo 1996; Sazima et al. 1996; Buzato et al. 2000; Lopes 2002; Dziedzioch et al 2003; Abreu \& Vieira 2004; Lasprilla \& Sazima 2004; Krömer et al. 2006; Canela 2006; Roccade-Andrade 2006). As flores visitadas pelos troquilídeos nas áreas de cerrado apresentaram uma variedade de coloração e formas que nem 
sempre estão associadas às preferências destas aves (sensu Faegri \& van der Pijl 1979). As flores com corolas amarelas e brancas somaram mais de $60 \%$ da flora registrada no estudo, enquanto que as cores laranja e vermelha, mais comumente associadas à ornitofilia, contribuíram com menos de $20 \%$. Estes dados corroboram o encontrado em outros estudos em áreas de cerrado (Araújo et al. 2013; Maruyama et al. 2013). Da mesma forma, as flores tubulares não foram as mais frequentes entre as espécies registradas. As flores do tipo goela e estandarte foram predominantes (mais de $60 \%$ do total). $\mathrm{O}$ tipo tubular também não foi o mais encontrado em outro estudo realizado em cerrado s.r. do CCPIU, onde a forma estandarte prevaleceu (Maruyama et al. 2013), mas foi o mais frequente em outros estudos que também envolveram fisionomias de mata (Araújo et al. 2013; Maruyama et al. 2013).

O maior número de espécies com outras síndromes em relação à ornitofilia tem sido frequentemente encontrado em estudos de flora visitada por beija-flores em ambientes de Cerrado (Borges 2000; Araújo et al. 2013; Maruyama et al. 2013), Pantanal (Araújo \& Sazima 2003), campos rupestres (Vascocelos \& Lombardi 2001, Machado et al. 2007), e Caatinga (Machado \& Lopes 2004; Machado 2009). Este comportamento generalista dos beija-flores, visitando flores de variadas síndromes, tem sido observado mesmo em ambientes com maior diversidade de espécies tipicamente ornitófilas como a Mata Atlântica (Rocca-de-Andrade 2006; Ferreira et al. [inédito]). Uma exceção a esta tendência seriam os campos de altitude, onde os beija-flores se restringem a plantas ornitófilas (Freitas \& Sazima 2006).

Este estudo e os demais realizados nas mesmas áreas de cerrado s.r. (Araújo et al. 2013; Maruyama et al. 2013) revelaram que a maioria das espécies cujas flores são visitadas por beijaflores apresentam porte arbóreo. Epífitas e lianas não são bem representadas em ambientes abertos e mais secos como o cerrado e provavelmente por isso não ocorreram neste estudo, nem em outro realizado no CCPIU (Maruyama et al. 2013), mas podem se apresentar em formações florestais do Cerrado (Araújo et al. 2011; Araújo et al. 2013). Estas formas, além das herbáceas, são mais comuns em formações de floresta ombrófila (Buzato et al. 2000; Lopes 2002; Araújo \& Sazima 2003; Dziedzioch et al. 2003; Canela 2006).

A floração anual, observada para todas as espécies, é comum em floras polinizadas por beija-flores em praticamente todos os ambientes já estudados (Abreu \& Vieira 2004; Canela 2006; Rocca-de-Andrade 2006; Leal et al. 2006; Machado et al. 2007; Machado 2009; Rodrigues 2011; Araújo et al. 2013). A duração intermediária nos períodos de floração (sensu Newstrom 1994) da maioria das espécies corroborou o encontrado em outro estudo no Panga (Araújo et al. 2013). A sobreposição de períodos propiciou a ocorrência de espécies florescendo durante todo ano. Esse modelo de comportamento fenológico tem sido relatado também para outras comunidades, disponibilizando recursos ao longo de todo ano e permitindo a permanência dos beija-flores (Buzato et al. 2000; Varassin 2002; Abreu \& Vieira 2004; Machado \& Semir 2006; Rocca-de-Andrade 2006; Machado et al. 2007; Machado 2009; Rodrigues 2011). As características fenológicas aqui registradas, no entanto, devem ser consideradas com cautela já que o estudo sistematizado foi feito em apenas treze meses, período insuficiente para a determinação de padrões (Newstrom et al. 1994).

Mesmo havendo espécies florescendo durante todo o ano, encontrou-se nas áreas estudadas uma maior quantidade de espécies ornitófilas e não ornitófilas em flor durante a estação seca. Resultados semelhantes foram observados em outros estudos no Panga, onde somente as espécies tipicamente ornitófilas floresceram mais na estação chuvosa em áreas de cerrado e campo sujo (Araújo et al. 2013; Maruyama et al. 2013). Outros estudos em biomas diferentes revelaram também maior número de espécies florescendo na estação seca como em uma área de Caatinga em Pernambuco (Leal et al. 2006) e em floresta seca do México (Arizmendi \& Ornelas 1990). A Mata Atlântica, ao contrário, exibe um pico de floração das espécies na estação chuvosa (Sazima et al. 1995; Araújo 1996; Buzato et al. 2000; Lopes 2002; Machado \& Semir 2006), o que ocorreu também nos capões do Pantanal (Araújo \& Sazima 2003), e em um fragmento florestal de Viçosa (Abreu \& Vieira 2004). Na Floresta Amazônica Colombiana (Lasprilla \& Sazima 2004), em floresta tropical úmida na Costa Rica (Stiles 1978) e em campos rupestres da Chapada Diamantina (Machado et al. 2007) houve picos de floração em ambos os períodos seco e chuvoso. Nos primeiro e segundo casos certamente por não haver grande diferenciação nos regimes de chuva ao longo do ano e no terceiro, os autores relatam a provável influência do regime de chuvas atípico 
ocorrido em alguns meses da estação seca no ano de estudo. Portanto, aparentemente, não há um padrão definido de floração em relação às estações seca e chuvosa, seja para ambientes secos ou úmidos (Buzato et al. 2000; Lopes 2002). Apesar de haver picos de floração em diferentes estações do ano, em diferentes lugares, o mais importante é que todos os estudos relatam haver néctar sendo ofertado aos beija-flores durante todo ano.

Os conjuntos de espécies de plantas visitadas por beija-flores em cada transecto e em cada área foram bastante similares entre si, contrastando com a grande diversidade beta descrita para a flora do Cerrado (Bridgewater et al. 2004). Estudos comparativos para a flora lenhosa do Cerrado mostraram uma grande variação na composição entre diferentes regiões do bioma, resultando numa alta $\beta$-diversidade e baixa similaridade (Borges 2000; Ratter et al. 2003; Bridgewater et al. 2004). No entanto, apesar da grande diversidade de espécies apresentada por diferentes regiões de Cerrado, quando se trata de áreas mais próximas ou em uma mesma região fitogeográfica, a similaridade entre elas tende a ser maior (Felfili et al. 2004; Lopes et al. 2011). Assim, a alta similaridade entre os transectos e áreas estudados pode ser explicada, em parte, pela proximidade entre eles. Ainda que o Parque Estadual da Serra de Caldas Novas seja uma área mais distante das demais no Triângulo Mineiro, pode-se considerar que as três áreas são relativamente próximas e a grande similaridade entre elas pode ser em função de se encontrarem em uma mesma região fitogeográfica (Bridgewater et al. 2004), com mais de $60 \%$ de similaridade quanto às espécies lenhosas (Lopes et al. 2011).

O número de espécies de beija-flores registrado neste estudo foi relativamente alto considerando a baixa ocorrência de espécies tipicamente ornitófilas. Além disso, quatro outras espécies foram registradas em outros estudos nas mesmas áreas, Amazilia lactea (Lesson 1832), Heliomaster squamosus (Temminck 1823), Polytmus guainumbi (Pallas 1764) e Phaethornis pretrei (Lesson \& Delattre 1839) totalizando 13 espécies ocorrendo na região. Isto representa mais de $30 \%$ das espécies citadas para o Cerrado (36) (Macedo 2002). Este número é relativamente alto quando comparado à maioria dos outros estudos realizados em diversos ambientes, com exceção de uma floresta tropical no Equador, onde foram registradas 26 espécies de beija-flores (Dziedzioch et al. 2003). A riqueza registrada para a região foi comparável a algumas áreas florestais no domínio Mata Atlântica (Araújo 1996; Buzato et al. 2000; Abreu \& Vieira 2004; Rocca-de-Andrade 2006), porém foi ainda maior que em outras áreas deste bioma (Sazima et al. 1996; Varassin \& Sazima 2000; Lopes 2002; Canela 2006; Machado \& Semir 2006). É possível que nestes ambientes florestais a riqueza de beija-flores seja subestimada pela frequente limitação dos estudos ao sub-bosque (Rocca-de-Andrade 2006). O número de espécies encontrado nas áreas de estudo também foi maior que em outros biomas como capões do Pantanal (Araújo \& Sazima 2003), Caatinga (Machado \& Lopes 2004; Machado 2009) e campos rupestres (Machado et al. 2007) onde foram registradas de quatro a oito espécies de beija-flores.

Todos os beija-flores observados neste estudo e a maioria nos outros realizados no Cerrado (Araújo et al. 2011; Araújo et al. 2013; Maruyama et al. 2013) pertencem à subfamília Trochilinae. Estes são os principais beija-flores, em número de espécies e em frequência de visitas, de áreas mais abertas como cerrado s.r., campo sujo, Caatinga e campos rupestres embora também ocorram em áreas de mata, onde normalmente são mais vistos nas bordas ou dossel (Feinsinger \& Colwell 1978; Stiles 1981). Os Phaethornithinae são polinizadores mais importantes em ambientes de mata e apenas uma espécie, Phaethornis pretrei, foi registrada visitando flores no Cerrado da região de Uberlândia, e normalmente era vista em matas de galeria ou próxima a elas (Maruyama et al. 2013; Araújo et al. 2013).

Do ponto de vista da importância que cada espécie exerce sobre a outra numa interação ecológica, em ambientes florestais os beija-flores são fundamentais para a reprodução de muitas espécies vegetais, muitas vezes sendo até mesmo seus únicos polinizadores efetivos. No entanto, em ambientes de Cerrado, ao que parece, as espécies vegetais que oferecem néctar são mais importantes para os beija-flores que vice-versa. Assim as espécies nectaríferas visitadas por eles, sendo elas ornitófilas ou não, são fundamentais para a persistência destas aves ao longo do tempo nas áreas de Cerrado.

\section{Agradecimentos}

À CAPES, a bolsa de Doutorado da primeira autora. Ao Clube de Caça e Pesca Itororó de Uberlândia e ao Parque Estadual da Serra de Caldas Novas por permitirem a realização do trabalho em suas dependências. 


\section{Referências}

Abreu, C.R.M. \& Vieira, M.F. 2004. Os beija-flores e seus recursos florais em um fragmento florestal de Viçosa, sudeste brasileiro. Lundiana 5: 129-134.

NIMER, E. 1989. Climatologia do Brasil. 2 ${ }^{\mathrm{a}}$ ed. IBGE, Rio de Janeiro. 421pp.

Araujo, A.C. 1996. Beija-flores e seus recursos florais numa área de planície costeira do litoral norte de São Paulo. Dissertação de Mestrado. Universidade Estadual de Campinas, Campinas. 69 pp.

Araújo, A.C. \& Sazima, M. 2003. The assemblage of flowers visited by hummingbirds in the "capões" of southern Pantanal, Mato Grosso do Sul, Brazil. Flora 189: 1-9.

Araújo, F.P.; Sazima, M. \& Oliveira, P.E. 2013. The assembly of plants used as nectar sources by hummingbirds in a cerrado area of Central Brazil. Plant Systematics and Evolution 299: 1119-1133.

Araújo, F.; Barbosa, A.A.A. \& Oliveira, P.E. 2011. Floral resources and hummingbirds on an island of flooded forest in Central Brazil. Flora 206: 827-835.

Arizmendi, M.C. \& Ornelas J.F. 1990. Hummingbirds and their floral resources in a tropical dry forest in Mexico. Biotropica 22: 172-180.

Barbosa, A.A.A. \& Sazima, M. 2008. Biologia reprodutiva de plantas herbáceo-arbustivas de uma área de campo sujo de cerrado. In: Sano, S.M.; Almeida, S.P. \& Ribeiro, J.F. (eds.). Cerrado Ecologia e Flora. V1. EMBRAPA. Planaltina, DF. 291-318.

Bridgewater, S.; Ratter, J.A. \& Ribeiro, J.F. 2004. Biogeographic patterns, $\beta$-diversidy and dominance in the cerrado biome of Brazil. Biodiversty and Conservation 13: 2295-2318.

Borges, H.B.N. 2000. Biologia reprodutiva e conservação do estrato lenhoso numa comunidade do cerrado. Tese de Doutorado. Universidade Estadual de Campinas, Campinas.160 pp.

Brower, J.E. \& Zar, J.H. 1984. Field \& laboratory methods for general ecology. Wm. C. Brown. $2^{\text {nd }}$ ed. Duduque, EUA. 226 pp.

Buzato, S.; Sazima, M. \& Sazima, I. 2000. Hummingbirdpollinated floras at three Atlantic forest sites. Biotropica 32: 824-841.

Canela, M.B.F. 2006. Interações entre plantas e beijaflores numa comunidade de Floresta Atlântica Montana em Itatiaia, RJ. Tese de Doutorado. Universidade Estadual de Campinas, Campinas. $75 \mathrm{pp}$.

Cardoso, E.; Moreno, M.I.C; Bruna, E.M. \& Vasconcelos, H.L. 2009. Mudanças fitofisionômicas no cerrado: 18 anos de Sucessão Ecológica na Estação Ecológica do Panga, Uberlândia-MG. Caminhos de Geografia 10: 254-268.

Carvalho, C.B.V. 1999. Memória e aprendizado: influência de características florais no padrão de forrageamento de beija-flores (Aves, Trochilidae). Dissertação de Mestrado. Universidade de Brasília, Brasília. 44 pp.

Carvalho, F.A.; Rodrigues, V.H.P.; Kilca, R.V.; Siqueira, A.S.; Araújo, G.M. \& Schiavini, I. 2008. Composição florística, riqueza e diversidade de um cerrado sensu stricto no sudeste do Estado de Goiás. Bioscience Journal 24: 64-72.

Costa, A.A. \& Araújo, G.M. 2001. Comparação da vegetação arbórea de cerradão e de cerrado na Reserva do Panga, Uberlândia, Minas Gerais. Acta Botanica Brasilica 15: 63-72.

Dalsgaard, B.; Gonzáles, A.M.M.; Olesen, J.M.; Ollerton, J.; Timmermann, A.; Andersen, L.H. \& Tossa, A.G. 2009. Plant-hummingbird interactions in the West Indies: floral specialisation gradients associated with environment and hummingbird size. Oecologia 159: 757-766.

Dziedzioch, C.; Stevens, A.D. \& Gottsberger, G. 2003. The hummingbird plant community of a tropical montane rain forest in Southern Ecuador. Plant Biology 5: 331-337.

Faegri, K. \& van der Pijl, L. 1979. The Principles of pollination ecology. Pergamon Press. Oxford. 244 pp.

Faleiro, W. 2007. Composição florística e estrutural da comunidade arbórea em duas áreas de cerrado sensu stricto, em Uberlândia-MG. Dissertação de Mestrado. Universidade Federal de Uberlândia, Uberlândia. 42 pp.

Feinsinger, P. \& Colwell, R.K. 1978. Community organization among neotropical nectar-feeding birds. American Zoologist 18: 779-795.

Felfili, J.M.; Felfili, M.C.; Nogueira, P.E.; Armas, J.F.S.; Farinas, M.R.; Nunes, M.; Silva-Júnior, C.M.; Rezende, A.V. \& Fagg, C.W. 2008. Padrões fitogeográficos e suas relações com sistemas de terras no bioma cerrado. In: Sano, S.M.; Almeida, S.P. \& Ribeiro, J.F. (eds.). Cerrado Ecologia e Flora. V1. EMBRAPA. Planaltina, DF. Pp. 213-228.

Felfili, J.M.; Silva-Júnior, C.M.; Sevilha, A.C; Fagg, C.W.; Walter, B.M.T.; Nogueira, P.E. \& Rezende, A.V. 2004. Diversity, floristic and structural patterns of cerrado vegetation in Central Brazil. Plant Ecology 175: 37-46.

Freitas, L. \& Sazima, M. 2006. Pollination biology in a tropical high-altitude grassland in Brazil: interactions at the community level. Annals of the Missouri Botanical Garden 93: 465-516.

Gottsberger, G. \& Silberbauer-Gottsberger, I. 2006. Life in the cerrado. V II. Pollination and seed dispersal - A South American tropical seasonal ecosystem. Reta Verlag, Ulm. 382 pp.

Grantsau, R. 1989. Os beija-flores do Brasil. Expressão e Cultura. Rio de Janeiro. 234 pp.

Krömer, T.; Kessler, M. \& Herzog, M. 2006. Distribution and flowering ecology of bromeliads along two climatically contrasting elevational transects in the Bolivean Andes. Biotropica 38: 183-195. 
Lasprilla, L.R. \& Sazima, M. 2004. Interacciones planta-colibrí en tres comunidades vegetales de la parte suroriental del Parque Nacional Natural Chiribiquete, Colombia. Ornitologia Neotropical 15: 183-190.

Leal, F.C.; Lopes, A.V. \& Machado, I.C. 2006. Polinização por beija-flores em uma área de caatinga no Município de Floresta, Pernambuco, Nordeste do Brasil. Revista Brasileira de Botânica 29: 379-389.

Lopes, A.V.F. 2002. Polinização por beija-flores em remanescente da mata atlântica pernambucana, Nordeste do Brasil. Tese de doutorado. Universidade Estadual de Campinas, Campinas. 131 pp.

Lopes, S.F.; Vale, V.S; Oliveira, A.P. \& Schiavini, I. 2011. Análise comparativa da estrutura e composição florística de cerrado no Brasil Central. Interciência 36: 8-15.

Macedo, R.H.F. 2002. The Avifauna: Ecology, biogeography, and behavior. In: Oliveira, P.S. \& Marquis, R.J. (eds.). The Cerrados of Brazil. Columbia University Press, New York. 242-265.

Machado, C.G. 2009. Beija-flores (Aves-Trochilidae) e seus recursos florais em uma área de Caatinga da Chapada Diamantina, Bahia, Brasil. Zoologia 26: 255-265.

Machado, C.G.; Coelho, A.G.; Santana, C.S. \& Rodrigues, M. 2007. Beija-flores e seus recursos florais em uma área de campo rupestre da Chapada Diamantina, Bahia. Revista Brasileira de Ornitologia 15: 215-227.

Machado, C.G. \& Semir, J. 2006. Fenologia da floração e biologia floral de bromeliáceas ornitófilas de uma área da Mata Atlântica do Sudeste brasileiro. Revista Brasileira de Botânica 29: 163-174.

Machado, I.C. \& Lopes, A.V. 2004. Floral traits and pollination systems in the Caatinga, a Brazilian tropical dry forest. Annals of Botany 94: 365-376.

Martins, F.Q. \& Batalha, M.A. 2006. Pollination systems and floral traits in cerrado woody species of the Upper Taquari region (Central Brazil). Brazilian Journal of Biology 66: 543-552.

Maruyama, P.K.; Oliveira, G.M.; Ferreira, C.; Dalsgaard, B. \& Oliveira, P.E. 2013. Pollination syndromes ignored: importance of non-ornithophilous flowers to Neotropical savanna hummingbirds. Naturwissenschaften 100: 1061-1068.

Newstrom, L.E.; Frankie, G.W. \& Baker, H.G. 1994. A new classification for plant phenology based on flowering patterns in lowland tropical rain forest at La Selva, Costa Rica. Biotropica 26: 141-159.

Oliveira, P.E. \& Gibbs, P.E. 2000. Reproductive biology of woody plants in a cerrado community of central Brazil. Flora 195: 311-329.

Oliveira, P.E. \& Gibbs, P.E. 2002. Pollination and reproductive biology in cerrado plant communities. In: Oliveira, P.S. \& Marquis, R.J. (eds). The
Cerrados of Brazil. Columbia University Press, New York. Pp. 329-347.

Ratter, J.A.; Bridgewater, S. \& Ribeiro, J.F. 2003. Analysis of the floristic composition of the Brazilian cerrado vegetation III: Comparison of the woody vegetation of 376 areas. Edinburgh Journal of Botany 60: 57-109.

Rocca-de-Andrade, M.A. 2006. Recurso floral para aves em uma comunidade de mata atlântica de encosta: sazonalidade e distribuição vertical. Tese de Doutorado. Universidade Estadual de Campinas, Campinas. 118 pp.

Rodrigues, L.C. 2011. Beija-flores e seus recursos florais em uma área de campo rupestre: composição de espécies, sazonalidade e rede de interações. Tese de Doutorado. Universidade Federal de Minas Gerais, Belo Horizonte. 118 pp.

Rosa, R.; Lima, S.C.C. \& Assunção, W.L. 1991. Abordagem preliminar das condições climáticas de Uberlândia (MG). Sociedade e Natureza 3: 91-108.

Sargent, R.D. \& Acherly, D.D. 2008. Plant-pollinator interactions and the assembly of plant communities. Trends in Ecology and Evolution 23: 123-130.

Sazima I.; Buzato, S. \& Sazima, M. 1995. The sawbilled hermit Ramphodon naevius and its flowers in southeastern Brazil. Journal of Ornithology 136: 195-206.

Sazima, I.; Buzato, S. \& Sazima, M. 1996. An assemblage of hummingbird-pollinated flowers in a montane forest in southeastern Brazil. Botanica Acta 109: 149-160.

Schiavini, I. \& Araújo, G.M. 1989. Considerações sobre a vegetação da Reserva Ecológica do Panga. Sociedade e Natureza 1: 61-66.

Sigrist, T. 2009. Avifauna Brasileira. Descrição das espécies. Avisbrasilis. Vinhedo, SP. 305 pp.

Silberbauer-Gottsberger, I. \& Gottsberger, G. 1988. A polinização de plantas do cerrado. Revista Brasileira de Biologia 48: 651-663.

Silva, L.O.; Costa, D.A.; Santo Filho, K.E.; Ferreira, H.D. \& Brandão, D. 2002. Levantamento florístico e fitossociológico em duas áreas de cerrado sensu stricto no Parque Estadual da Serra de Caldas Novas, Goiás. Acta Botanica Brasilica 16: 43-53.

Stiles, F.G. 1978. Temporal organization of flowering among the hummingbirds foodplants of a tropical wet forest. Biotropica 10: 194-210.

Stiles, F.G. 1981. Geographical aspects of bird-flower coevolution, with particular reference to Central America. Annals Missouri Botanical Garden 68: 323-351.

Varassin, I.G. 2002. Estrutura espacial e temporal de uma comunidade de Bromeliaceae e seus polinizadores em floresta atlântica no sudeste do Brasil. Tese de Doutorado. Universidade Estadual de Campinas, Campinas. 96p. 
Varassin, I.G. \& Sazima, M. 2000. Recursos de Bromeliaceae utilizados por beija-flores e borboletas em Mata Atlântica no Sudeste do Brasil. Boletim do Museu de Biologia Mello Leitão 11/12: 57-70.
Vasconcelos, F.V. \& Lombardi, J.A. 2001. Hummingbirds and their flowers in the campos rupestres of southern Espinhaço Range, Brazil. Melopsittacus 4: 3-30. 